\title{
Preparation of in-situ compatibilized PLA/starch composites and its non-isothermal pyrolysis kinetics
}

\author{
Li Chong ${ }^{1,2,3}$, Sun Zhiyuan, ${ }^{1,4^{*}}$, He Xiaohong ${ }^{1}$, Peng Lin ${ }^{1}$, Lv Jingmei ${ }^{1}$, Zhan Shijing ${ }^{1}$, Liu Hongbo ${ }^{1,2,3 * *}$, Xiong Zhiyong ${ }^{1}$, \\ Guo Bingzhi ${ }^{1}$, Liao Zhengfu ${ }^{5}$, Jiao Qingze ${ }^{1,3}$ \\ ${ }^{1}$ School of materials and environment, Beijing Institute of Technology, Zhuhai 519088, China \\ ${ }^{2}$ Zhuhai Tianwei Pegasus Printing Supplies Co., Ltd. Zhuhai 519060, China \\ ${ }^{3}$ School of Chemistry and Chemical Engineering, Beijing Institute of Technology, Beijing 102488, China; \\ ${ }^{4}$ Institute of Chemistry Chinese Academy of Sciences, Beijing 100190, China \\ ${ }^{5}$ Faculty of Materials and Energy, Guangdong University of Technology, Guangzhou 510006, China
}

\begin{abstract}
A fully degradable PLA/starch composite was prepared by one-step in-situ compatibilization method. The effects of raw materials ratio and maleic anhydride (MAH) dosage were studied by thermogravimetric analyzer (TG) and scanning electron microscopy (SEM). The thermal stability and microstructure of the composites were investigated, and the non-isothermal thermal decomposition kinetics of the composites were discussed. The DTG results show that there are two distinct maximum decomposition rate peaks in the unmodified composites. After the MAH is added, the maximum decomposition rate peaks of the composites are close to each other. In addition, as the MAH dosage increases, the maximum rate of decomposition peak gradually shifts to a lower temperature. The SEM results show that the compatibility of the composites is improved after the addition of MAH. And both the Kissinger and Flynn-Wall-Ozawa methods are well described for the non-isothermal thermal decomposition kinetics of PLA and PLA/starch composites.
\end{abstract}

\section{Introduction}

Synthetic polymers have brought great convenience to industrial, agricultural production and human daily life, yet have also caused serious environmental pollution problems. Therefore, biodegradable polymer materials have received much attention in recent years[1-2]. With the rapid development of commercialization of biodegradable plastic products, biodegradable materials have been widely used in packaging [3-4], agriculture [56], medical [7-8], 3D printing [9-11] and other fields.

Polylactic acid (PLA) is a new type of biodegradable polymer with good thermoplasticity, processability and biocompatibility. However, PLA also has disadvantages such as high production cost, low crystallization rate, and high brittleness, thus limiting its wide application. Starch is a completely biodegradable natural polymer material, which is favored by most researchers because of its abundant source and low price. A large number of studies have used starch to modify PLA [12-14] to reduce the cost of PLA and improve the biodegradability of the material.

However, hydrophobic PLA and hydrophilic starch are thermodynamically incompatible systems, resulting in weak interfacial adhesion between the two components after blending, and the mechanical properties of the prepared materials are poor [15]. In-situ compatibilization is an important method for preparing high performance polymer materials. By simple melt blending, the compatibilizer reacts with other components to form a graft copolymer or a block copolymer in situ, thereby improving the interfacial adhesion of the two incompatible phases [16]. The process often adopts a "one-step method", that is, the composite material compatibilization and melting \& blending complete simultaneously, which does not require any solvent.

In this paper, maleic anhydride (MAH) was used as a compatibilizer to prepare a fully biodegradable PLA/starch composite by in-situ compatibilization. The effects of raw materials ratio and MAH content on the thermal stability and microstructure of the composites were investigated. The thermal decomposition kinetics of the composites were studied by Kissinger and FlynnWall-Ozawa methods.

\section{Materials and methods}

\subsection{Materials Ma}

PLA(4032D) was purchased from American Nature Works, American. Starch, Food Grade, was purchased from Unilever (China) Co., Ltd.. Glycerol: Analytically pure, was purchased from Tianjin Fuyu Fine Chemical Co., Ltd., China. Maleic anhydride (MAH), Analytically pure, was purchased from Tianjin Damao Chemical Reagent Factory, China. Dicumyl

\footnotetext{
* Corresponding author: sunzy0128@163.com
} 
peroxide (DCP), Analytically pure, was purchased from Shandong West Asia Chemical Co., Ltd., China.

\subsection{Preparation of composite materials}

The PLA and starch were placed in a constant temperature oven and dried. The dried starch and the glycerin (plasticizer) are initially mixed according to the formula, and then mixed with a certain amount of PLA, MAH and initiator DCP, and the mixture is uniformly mixed by a torque rheometer (XXS-300). Mixing conditions: zone I, $175^{\circ} \mathrm{C}$, zone II, $180^{\circ} \mathrm{C}$, zone III, $175^{\circ} \mathrm{C}, 35 \mathrm{r} / \mathrm{min}, 16 \mathrm{~min}$.

\subsection{Characterization}

\subsubsection{Scanning electron microscope}

Images of the morphologies of samples were obtained using a scanning electron microscope (model FEI Quanta FEG 250, Hillsboro, Oregon, USA) operated in secondary electron mode, with a beam current of $100 \mathrm{~mA}$ and an accelerating voltage of $20 \mathrm{kV}$. Prior to analysis, the sample were frozen and chopped under liquid nitrogen, and coated with a thin layer of gold using as a vacuum coater to prevent charging.

\subsubsection{Thermogravimetric analysis}

The thermal stabilities of JSE and JL were studied using a thermogravimetric analyzer (TG209 F3, Netzsch, Selb, Germany). Approximately $6 \mathrm{mg}$ of sample was heated from 30 to $500^{\circ} \mathrm{C}$ at a heating rate of $10{ }^{\circ} \mathrm{C} / \mathrm{min}$. Nitrogen gas at a flow rate of $50 \mathrm{ml} / \mathrm{min}$ was used to protect samples from oxidation.

\subsubsection{Non-isothermal pyrolysis kinetics}

The test sample had a mass of about $5 \mathrm{mg}$, nitrogen atmosphere, and a flow rate of $50 \mathrm{ml} / \mathrm{min}$. The heating rates were $5,10,15$, and $20^{\circ} \mathrm{C} / \mathrm{min}$, respectively.

\section{Results and Discussion}

\subsection{Thermal performance analysis of composite materials}

\subsubsection{TG Analysis of Composite Materials with Different Blending Ratios}

Figure 1 shows the TG and DTG curves for different ratios of PLA/starch composites. Firstly, it can be seen from the figure that when the starch content is higher, the initial thermal decomposition temperature(Ti) of the composite material is lower, indicating that the thermal stability of the composite material decreased by increasing the starch content. Secondly, the blend system has two distinct maximum decomposition rate peaks, the corresponding temperatures are $330^{\circ} \mathrm{C}$ and $390^{\circ} \mathrm{C}$, which are the decomposition peaks of starch and PLA, respectively, indicating that the interaction between PLA and starch is weak. This is due to the fact that there are many hydrophilic hydroxyl groups in the starch structure, and many hydrophobic ester groups in the PLA molecular chain. The two polymer are thermodynamically incompatible.
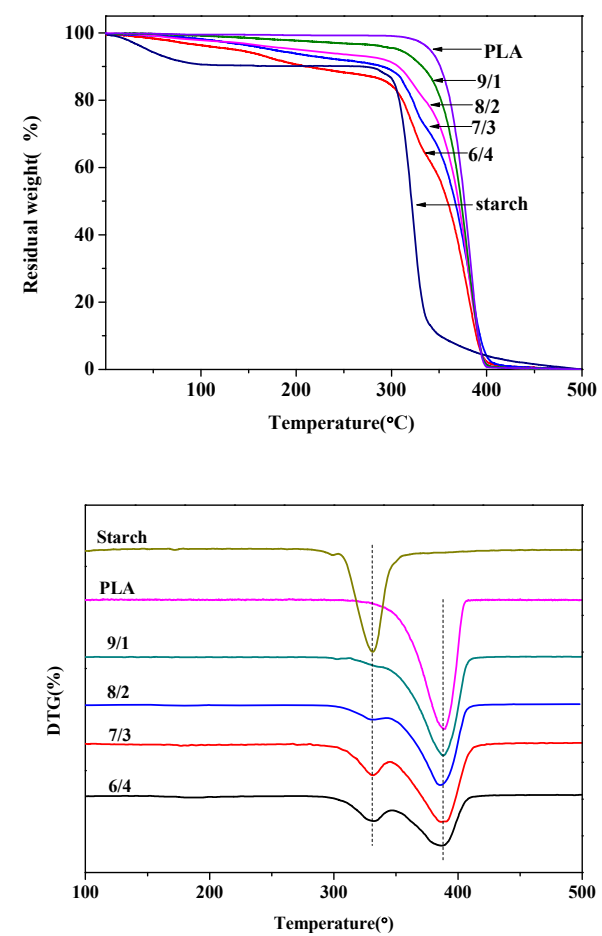

Fig.1. TG and DTG curves of different blending ratio

PLA/starch composites

Figure 2 is the TG and DTG curves of PLA-g$\mathrm{MAH} /$ starch composites with different blend ratios. It can be seen from the figure that as the starch content increases, the $\mathrm{Ti}$ of the composite material gradually decreases. When the composite ratio is $9 / 1$, there are two peaks in the DTG curve, whose temperatures are $358^{\circ} \mathrm{C}$ and $379^{\circ} \mathrm{C}$. The maximum decomposition rate peak temperature (Td) of PLA is $379^{\circ} \mathrm{C}$. Due to the high PLA content in this ratio, there are a small amount of PLA grafted products and a large amount of PLA in the system. After adding MAH, a new graft product is formed (PLA-g-MAH), so that the Td of the composite moves toward the low temperature peak of $358^{\circ} \mathrm{C}$. When the ratio is $8 / 2$, there is only one $\mathrm{Td}$, and the corresponding temperature is $358^{\circ} \mathrm{C}$. This is because the maximum decomposition rate of PLA and starch gradually approach due to the interaction with each other, and the two peaks coincide to form a peak. With the increase of the amount of starch, when the ratio of PLAg-MAH/starch is $7 / 3,6 / 4$, the two maximum decomposition rate peaks appear, and the two maximum decomposition rate peaks are close to each other, partially overlapping, and the spacing of two peaks reduced. This is because as the amount of starch gradually increase, the compatibility between PLA and starch becomes worse, and the interaction force is also weaker, so two peaks appear. After the addition of MAH, a graft polymer of PLA and MAH is formed at the phase interface, and the formed graft polymer can continue to form a chemical bond with the hydroxyl group in the starch [17]. The effect 
between polylactic acid and starch becomes stronger, so that the starch with lower thermal stability induces the maximum decomposition rate peak of PLA to move toward the low temperature direction, so the spacing between the two peaks decreases and approaches each other.
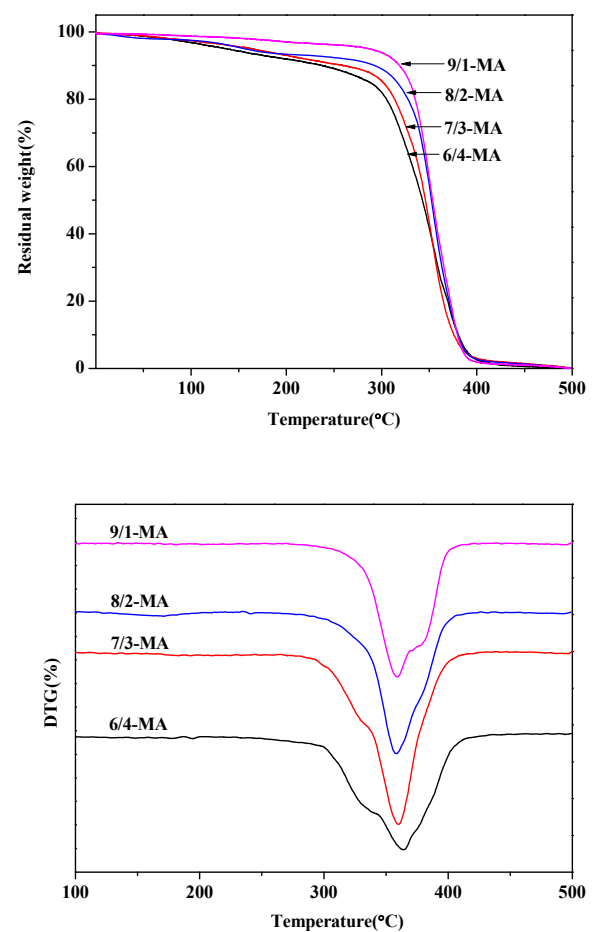

Fig.2. TG and DTG curves of PLA-g-MAH/starch composites with different blend ratios

\subsubsection{TG Analysis of Composite Materials with Different MAH Contents}

The thermogravimetric analysis results of composites with different MAH dosages are shown in Figure 3 and Table 1. It can be seen from the TG curve of Fig. 3 that the Ti of the composite without MAH is higher than that of the composite with MAH, and the Ti of the composite is lower when the MAH content is higher. It can be seen from the DTG curve that the composite without MAH has two peaks at $331^{\circ} \mathrm{C}$ and $386^{\circ} \mathrm{C}$, which are the peaks corresponding to the maximum decomposition rates of PLA and starch, respectively. In the PLA-g-MAH/starch composite, the Td of starch disappeared. As the amount of MAH increases, the peak of the maximum decomposition rate of the composite material gradually shifts toward the low temperature, which is due to increase of the mutual interaction between PLA and starch, and the two maximum decomposition rate peaks are close to each other. In addition, it also shows an increase in the content of MAH improves the compatibility of PLA and starch.
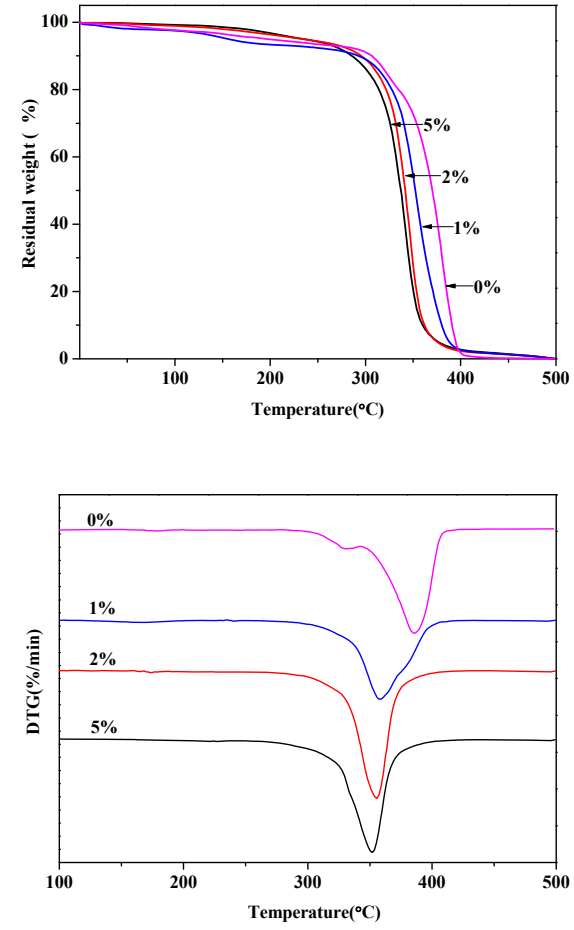

Fig.3. TG and DTG curves of composites with different MAH levels

Table 1. DTG data of composite materials with different MAH levels

\begin{tabular}{ccccccc} 
& PL & Starc & $0 \% \mathrm{MA}$ & $1 \% \mathrm{MA}$ & $2 \% \mathrm{MA}$ & $3 \% \mathrm{MA}$ \\
& $\mathrm{A}$ & $\mathrm{h}$ & $\mathrm{H}$ & $\mathrm{H}$ & $\mathrm{H}$ & $\mathrm{H}$ \\
\hline $\mathrm{Td}$ & 390 & 330 & $331 / 38$ & 359 & 355 & 351 \\
${ }^{\circ} \mathrm{C}$ & \multicolumn{7}{c}{6} & & & \\
\hline
\end{tabular}

\subsection{Micromorphological analysis}

It can be clearly observed From Fig.4(a,b) that there is a large amount of incompletely starchized starch, which is covered with a large number of grooves and voids, showing a distinct "island" structure, a clear two-phase interface of starch granules and PLA matrix. There was a significant phase separation between the Two-phase structure, indicating that both starch and PLA are noncompatible. Figure $4(\mathrm{c}, \mathrm{d})$ is a composite material modified with MAH compatibilization. As shown in the figure, the profile of PLA-g-MAH/starch composite is smooth and flat, and there is almost no large groove between PLA and starch. There is no obvious phase interface between the voids and the two phases. The two phases are more closely bonded, indicating that the addition of MAH has a compatibilizing effect on the system and improves the bonding between PLA and starch. This is because the PLA-g-MAH graft exists at the phase interface of the modified composite, and the carboxyl group on the molecular chain of the graft polymer can continue to react with the hydroxyl group of the starch to form an ester bond. Strong chemical bonding makes the interaction of the two phases between PLA and starch enhanced and the bond stronger. 

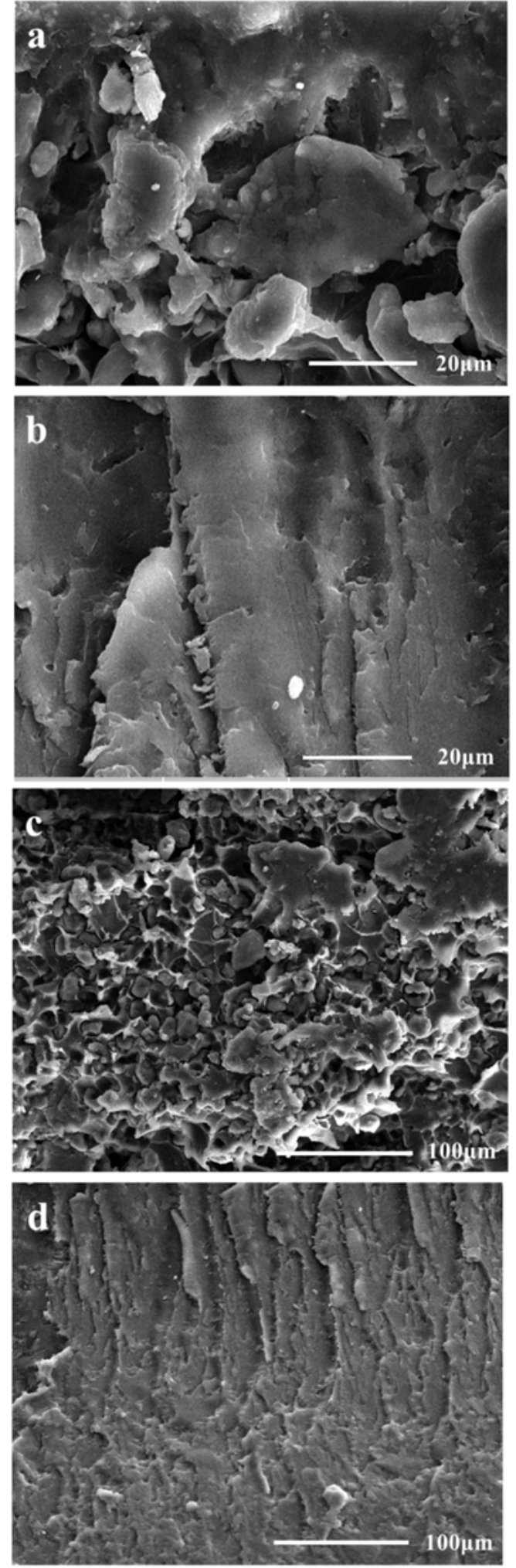

Fig.4. Microscopic topography of PLA/starch $(a, b)$ and PLA-g-MAH/starch (c, d)

\subsection{Non-isothermal pyrolysis behavior of PLA/starch composites}

As can be seen from Figure 5, the DTG curve of starch has two peaks due to the presence of different amounts of amylose and amylopectin in corn starch [18]. It can also be seen from the figure that as the heating rate increases,

the peak of the maximum decomposition rate of the composite moves to the high temperature side and gradually forms a large peak. This is because when the same target temperature is reached, the faster the temperature rise, the shorter the time required, and the lower the degree of reaction [19]. In addition, an increase of the rate of temperature rise causes the thermal hysteresis to increase, and the temperature at which the maximum rate of thermal decomposition of the material is moved to the high temperature side.
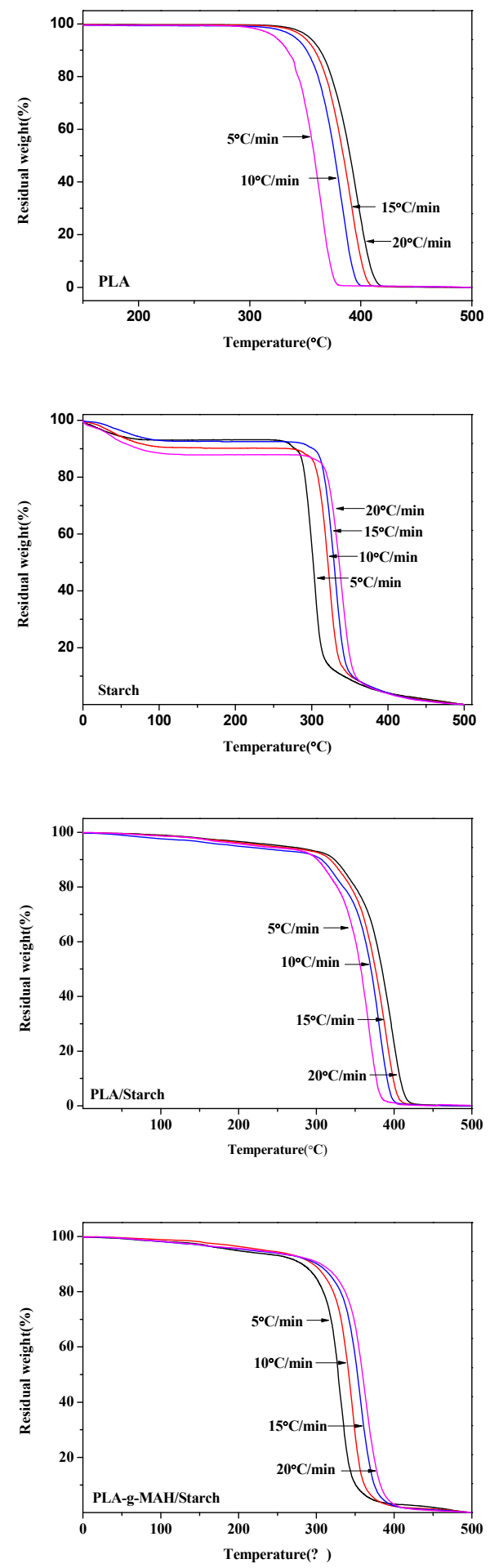

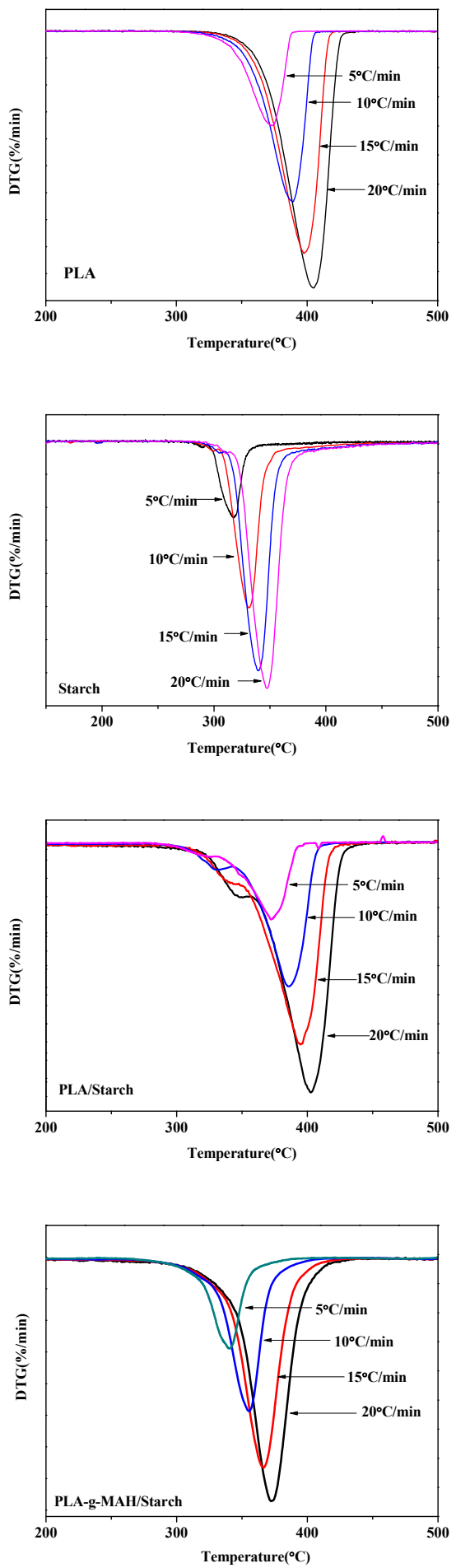

Fig.5. TG and DTG curves of PLA-g-MAH/starch with different heating rates

\subsection{Non-isothermal pyrolysis kinetics of PLA/starch composites}

\subsubsection{Non-isothermal kinetics by Kissinger method}

In order to further explore the thermal stability and thermal decomposition mechanism of PLA/starch composites, the thermal decomposition kinetics of composites were further investigated by Kissinger [20] and Flynn-Wall-Ozawa [21] methods, and the thermal decomposition activation energy were calculated $(\mathrm{E})$. The Kissinger method is a approach of kinetic analysis by a differential way, which depends on the relationship between the peak temperature Tm on the thermal analysis curve and the heating rate. The Kissinger method equation (1).

$$
\ln \frac{\beta}{T_{\mathrm{m}}^{2}}=\ln \frac{A R}{E_{\mathrm{k}}}-\frac{E_{\mathrm{k}}}{R T_{\mathrm{m}}}
$$

Where, $\beta$ - heating rate, $\mathrm{K} / \mathrm{min}$.

$\mathrm{T}_{\mathrm{m}}$ - peak temperature.

A- Arrhenius refers to the pre-factor, $1 / \mathrm{s}$.

$\mathrm{E}_{\mathrm{k}}$ - Apparent activation energy, $\mathrm{KJ} / \mathrm{mol}$, usually a larger value indicates a higher thermal stability of the material.

R- ideal gas constant, $8.314 \mathrm{~J} \bullet \mathrm{mol}-1 \cdot \mathrm{K}^{-1}$.

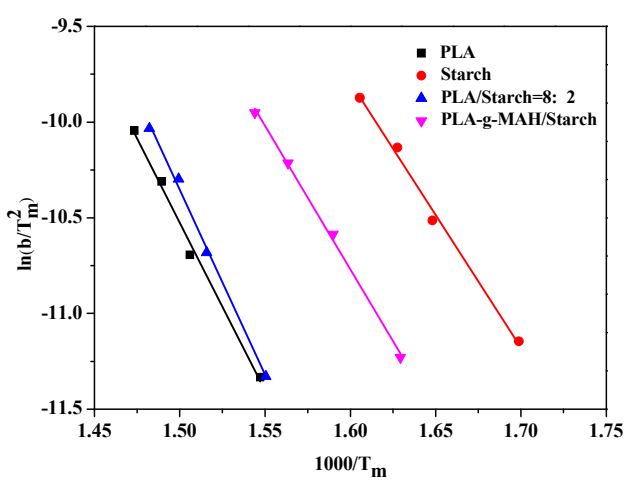

Fig.6. Kissinger method of $\ln \left(\beta / \mathrm{T}_{\mathrm{m}}{ }^{2}\right)$ and $1000 / \mathrm{T}_{\mathrm{m}}$ relationship fitting curve

According to the equation (1), the DTG curve is obtained at different heating rates $\beta$, and the corresponding peak temperature is found. Then, a linear regression is performed on $1 / \mathrm{T}_{\mathrm{m}}$, and a straight line is obtained. The apparent activation energy $E_{k}$ is obtained from the slope of the straight line, and the Pre-factor A is obtained from intercept, the results are shown in Table 2.

Table 2. The resulting of $E_{k}, \ln A$ and $R^{2}$ by the Kissinger method

\begin{tabular}{cccc}
\hline sample name & $\begin{array}{c}E_{\mathrm{k}} \\
(\mathrm{KJ} / \mathrm{mol})\end{array}$ & $\ln \mathrm{A}$ & $\mathrm{R}^{2}$ \\
\hline PLA & 146.14 & 18.71 & 0.994 \\
Starch & 115.27 & 15.02 & 0.995 \\
PLA/Starch =8:2 & 160.64 & 21.59 & 0.997 \\
$\begin{array}{c}\text { PLA-g- } \\
\text { MA/Starch=8:2 }\end{array}$ & 124.81 & 15.96 & 0.998 \\
(2\%MAH) & & & \\
\hline
\end{tabular}

\subsubsection{Non-isothermal pyrolysis kinetics by Ozawa ( $F$ -} W-O) method

The Ozawa method uses different temperatures corresponding to the same conversion rate to solve the activation energy on the TG curves of different heating rates. The Ozawa method avoids the reaction mechanism function and directly obtains the E value, avoiding the 
error that may be caused by the difference in the reaction mechanism function. Ozawa (F-W-O) method Equation (2).

$$
\log F(\alpha)=-0.4576 \frac{E_{\alpha}}{R T}-2.315+\log \frac{A E_{\alpha}}{R}-\log \phi
$$

Where, $\mathrm{F}(\alpha)$ - the integral form of the conversion function;

$\mathrm{E}_{\mathrm{a}}$ - static activation energy $(\mathrm{KJ} / \mathrm{mol})$;

A- the pre-index factor;

$\Phi$ - heating rate $\left({ }^{\circ} \mathrm{C} / \mathrm{min}\right)$;

$\mathrm{R}$ - gas universal constant;

$\mathrm{T}$ - absolute temperature $(\mathrm{K})$

Equation (3) can be derived from equation (2) when the heating rates are the same at different conversion rates.

$$
\log \phi=\log \left(\frac{A E_{\alpha}}{R}\right)-\log [-\ln (1-\alpha)]-2.315-0.4567 \frac{E_{\alpha}}{R T}
$$

Using $\log \Phi$ to $1 / \mathrm{T}$ as an equation, the apparent activation energy can be obtained from the slope, and the results are shown in Figure 7 and Table 3.
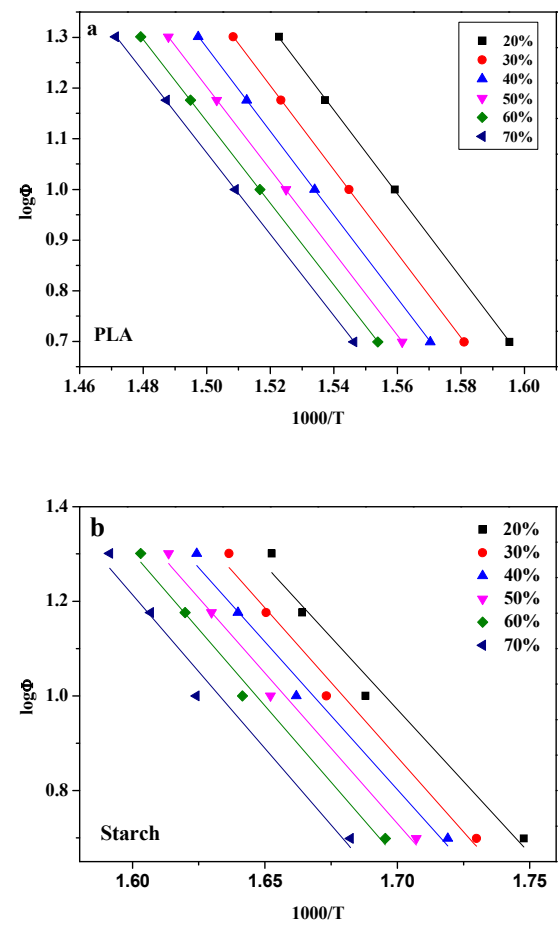
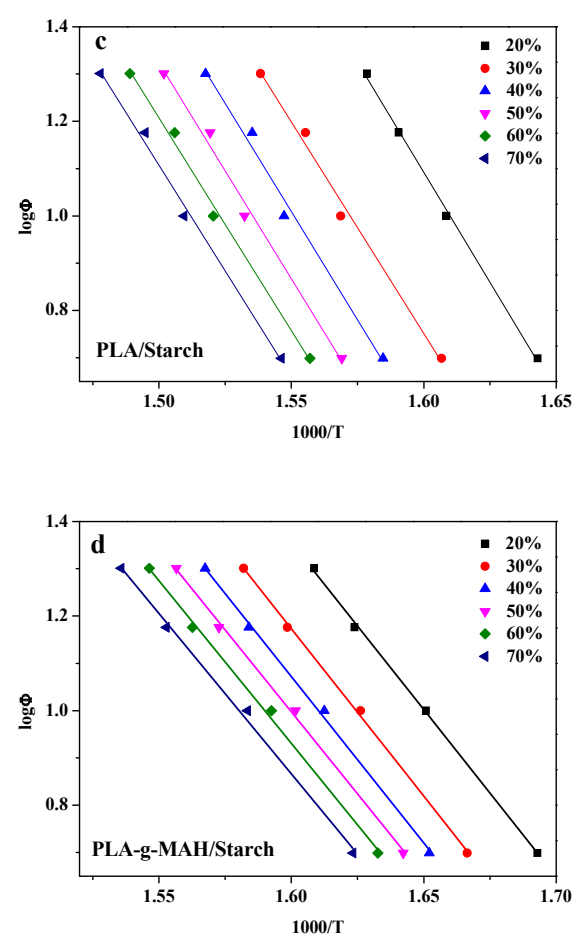

Fig.7. Fitting curve of PLA-g-MAH / starch with Ozawa

(F-W-O) method

Figures 6 and 7 are the curves obtained by fitting the Kissinger equation and the Ozawa equation. The relevant kinetic parameters are shown in Tables 2 and 3, respectively. The curves obtained by the two methods have a good linear relationship.

It can be seen from Tables 2 and 3 that the results of the pyrolysis activation energy $(\mathrm{Ea})$ calculated by the two methods are basically the same, indicating that both calculation methods are applicable to the PLA/starch blend system. The Ea of the composite material is: PLA/starch $>$ PLA $>$ PLA-g-MAH/starch $>$ starch,

$\mathrm{PLA} /$ starch has the largest Ea, which is due to the effect of starch on PLA as a nucleating agent [22]. The improved crystallinity increases the Ea of the composite. In addition, starch is a natural polymer having a cyclic structure, and has poor compatibility with PLA. The added starch can be used as a filler to a certain extent, and therefore, the movement of the PLA molecular chain during the heating process is suppressed. Moreover, the starch is not uniformly dispersed in the PLA, and the phase interface of the blending system is relatively obvious and there are many gaps, so the heat transfer process is slow during the heating process. In summary, the Ea of PLA/starch is higher than that of pure PLA. For PLA-g-MAH/starch composites, on the one hand, MAH is grafted onto PLA, so many side chains are grafted on the PLA main, and the increase of side chains leads to a decrease in the decomposition temperature of PLA. On the other hand, MAH grafted onto PLA can continue to react with the hydroxyl groups of starch, enhancing the interaction between PLA and starch, so the Ea of PLA-g-MAH/starch is between that of PLA and starch. 
Table 3. Results of PLA/starch blends by Ozawa (F-W-O)

\begin{tabular}{|c|c|c|c|c|c|c|}
\hline $\begin{array}{l}\mathrm{sa} \\
\mathrm{mp} \\
\mathrm{le}\end{array}$ & $\begin{array}{c}\text { conversio } \\
\text { n rate } \\
/ \alpha\end{array}$ & slope & $\begin{array}{l}\text { Inter } \\
\text { cept }\end{array}$ & $\mathrm{R}^{2}$ & $\begin{array}{l}\mathrm{E}(\mathrm{KJ} \cdot \\
\left.\mathrm{mol}^{-1}\right)\end{array}$ & $\mathrm{E}_{\mathrm{a}}$ \\
\hline & 0.2 & -8.27 & 13.89 & 0.999 & 150.55 & \\
\hline & 0.3 & -8.28 & 13.80 & 1 & 150.73 & \\
\hline PL & 0.4 & -8.25 & 13.66 & 1 & 150.19 & 148.9 \\
\hline \multirow[t]{5}{*}{ A } & 0.5 & -8.18 & 13.47 & 1 & 148.91 & 4 \\
\hline & 0.6 & -8.07 & 13.25 & 1 & 146.91 & \\
\hline & 0.7 & -8.04 & 13.14 & 1 & 146.36 & \\
\hline & 0.2 & -6.08 & 11.31 & 0.969 & 110.68 & \\
\hline & 0.3 & -6.30 & 11.58 & 0.979 & 114.69 & \\
\hline Sta & 0.4 & -6.46 & 11.78 & 0.985 & 117.60 & 117.8 \\
\hline \multirow[t]{4}{*}{$\mathrm{rch}$} & 0.5 & -6.58 & 11.90 & 0.989 & 119.79 & 1 \\
\hline & 0.6 & -6.69 & 12.01 & 0.991 & 121.79 & \\
\hline & 0.7 & -6.72 & 11.97 & 0.970 & 122.33 & \\
\hline & 0.2 & -9.30 & 15.98 & 0.998 & 169.30 & \\
\hline PL & 0.3 & -8.94 & 15.06 & 0.991 & 162.75 & \\
\hline $\mathrm{A} / \mathrm{s}$ & 0.4 & -9.15 & 15.19 & 0.988 & 166.57 & 165.2 \\
\hline $\operatorname{tar}$ & 0.5 & -9.13 & 15.02 & 0.991 & 166.21 & 1 \\
\hline \multirow[t]{2}{*}{$\mathrm{ch}$} & 0.6 & -8.99 & 14.7 & 0.994 & 163.66 & \\
\hline & 0.7 & -8.94 & 14.52 & 0.995 & 162.75 & \\
\hline PL & 0.2 & -7.06 & 12.65 & 0.999 & 128.52 & \\
\hline A- & 0.3 & -7.07 & 12.49 & 0.999 & 128.71 & \\
\hline g- & 0.4 & -7.03 & 12.32 & 0.998 & 127.98 & \\
\hline M & 0.5 & -6.94 & 12.09 & 0.998 & 126.34 & 126.7 \\
\hline A & 0.6 & -6.88 & 11.94 & 0.997 & 125.25 & 0 \\
\hline $\mathrm{H}$ & & & & & & \\
\hline $\begin{array}{l}\text { /sta } \\
\text { rch }\end{array}$ & 0.7 & -6.78 & 11.72 & 0.997 & 123.43 & \\
\hline
\end{tabular}

\section{Conclusion}

In this paper, a fully degradable PLA/starch composite was prepared by one-step in-situ compatibilization method. The effects of the ratio of raw materials and the amount of compatibilizer (maleic anhydride) on the microstructure and thermal properties of the composites were investigated. The Kissinger and Ozawa methods were used for the non-isothermal pyrolysis kinetics of the composites. The results show that there are two distinct maximum decomposition rate peaks in the unmodified composites. After the addition of MAH, the maximum decomposition rate peaks of the composites are close to each other. In addition, as the MAH dosage increases, the maximum rate of decomposition peak gradually shifts to a lower temperature. And the compatibility of the composites is improved after the addition of MAH. Moreover, both the Kissinger and Flynn-Wall-Ozawa methods are well described for the non-isothermal thermal decomposition kinetics of PLA and PLA/starch composites.

\section{Acknowledgements}

The authors acknowledge financial support from the Guangdong University Key Platforms and Research Projects Characteristic Innovation Projects (No. 2018KTSCX304).

\section{References}

1. Cao Y, Yin J, Yan S. Polymer bullettin 10,90(2016).

2. Matta A K, Rao R U, Suman K N S. Procedia materials science 6,1266(2014).

3. Scarfato P, Maio L D, Incarnato L.Journal of Applied Polymer Science 132,1(2015).

4. Marcin M, Agnieszka W, Leszek M. Thermoplastic Starch: A Green Material for Various Industries 3,1(2010).

5. Davoodi S, Oliaei E, Davachi S M. Rsc Advances 6, 42611(2016).

6. Vercelheze A E S, Marim B M, Oliveira A L M. Applied microbiology and biotechnology 103, 2193( 2019).

7. Vacaras S, Baciut M, Lucaciu O. Drug metabolism reviews 5,43(2019).

8. Shahrezaee M, Salehi M, Keshtkari S. Nanomedicine: Nanotechnology, Biology and Medicine 14,2061(2018).

9. Pisani S, Dorati R, Conti B. Reactive \& Functional Polymers 124,77(2018).

10. Li C, Wang F, Chen P. Journal of the Mechanical Behavior of Biomedical Materials 75,455(2017).

11. Arjmandi R, Hassan A, Eichhorn S J. Journal of Materials Science 50,3118(2015).

12. Lv S, Gu J, Tan H. Journal of Applied Polymer Science 134, 1(2017).

13. Shirai M A, Zanela J, Kunita M H. Advances in Polymer Technology 37,332(2018).

14. Zuo Y, Gu J, Yang L. International Journal of Biological Macromolecules 64,174(2014).

15. Bolay N L, Lamure A, Leis N G. Chemical Engineering \& Processing Process Intensification 56,1(2012).

16. Koh J J , Zhang X, He C. International Journal of Biological Macromolecules 109, 99(2018).

17. Ojijo V, Sinha Ray S, Sadiku R. ACS applied materials \& interfaces 5, 4266(2013).

18. Zuo Y F, Gu J, Qiao Z. International Journal of Biological Macromolecules 72, 391(2015).

19. Martens B M J, Gerrits W J J , Bruininx E M A M. Journal of Animal Science and Biotechnology 9,115(2018).

20. Kissinger H E. Analytical Chemistry 29,1702(1957)

21. Flynn J H, Wall L A. Journal of Polymer Science Part C Polymer Letters 4,323(1966).

22. Zhang $\mathrm{G}, \mathrm{Xu} \mathrm{C}, \mathrm{Wu}$ D. Industrial \& Engineering Chemistry Research 57,6257( 2018). 